\title{
History of osteopathic medical education accreditation
}

\author{
AOA EDITORIAL DEPARTMENT
}

Since its inception, the osteopathic profession has been concerned about the quality of osteopathic medical education and the training of well-prepared, qualified physicians.

A number of osteopathic colleges were established in the last decade of the 19th century. As with many other medical colleges of their time, they shared a lack of uniformity in admission and graduation requirements. In these early years, osteopathic medical educators and leaders recognized the fact that the attainment and maintenance of high educational standards were essential to produce high-quality, competent osteopathic physicians.

In 1897, the American Association for the Advancement of Osteopathy (AAAO) was formed. Its constitution provided for a number of committees, among which was the Committee on Education.

The concept of inspection and approval of osteopathic medical colleges was introduced in 1901 when the AAAO reorganized and became the American Osteopathic Association. Its new constitution provided that the Committee on Education, together with the Executive Committee of the Associated Colleges of Osteopathy (ACO), should constitute a joint committee. This group would investigate schools applying for membership in the ACO, make annual investigations of the conditions in the schools that were already members, and prepare an annual report for the AOA Board of Trustees.

To encourage more uniform quality in educational standards among its members, the
AOA also restricted eligibility for membership to graduates of approved schools.

The first osteopathic college inspection was made in 1903, and the members of the ACO were approved.

With these actions, the AOA established itself as the body responsible for accreditation standards for the profession. Its authority and expertise were recognized by other medical organizations at the time, as well as by state legislators. Many years were to pass, however, before the AOA received full recognition on a federal level.

In 1923, the AOA Department of Education became the Bureau of Professional Education; 2 years later, the Bureau on Colleges was added. These committees later joined to become the Bureau of Professional Education and Colleges. This group was charged with the responsibility for inspection of osteopathic medical colleges.

Initially, the colleges were inspected every 2 years, and then-when the number of colleges began to grow-every 3 years. Today, the osteopathic medical colleges receive a full survey every 5 years by a survey team representing all major preclinical and clinical science disciplines. An annual report is required for each approved osteopathic medical college during the nonsurvey years.

In 1960, the education structure of the AOA was reorganized. In order to bring all facets of osteopathic medical education under one body, a new Bureau of Professional Education was created. The restructured group then became responsible for postdoctoral and continu(continued on page 995) 
Pfizer Cost-Effectiveness Series:

An Important Message

Concerning the Costs of Treating Arthritis

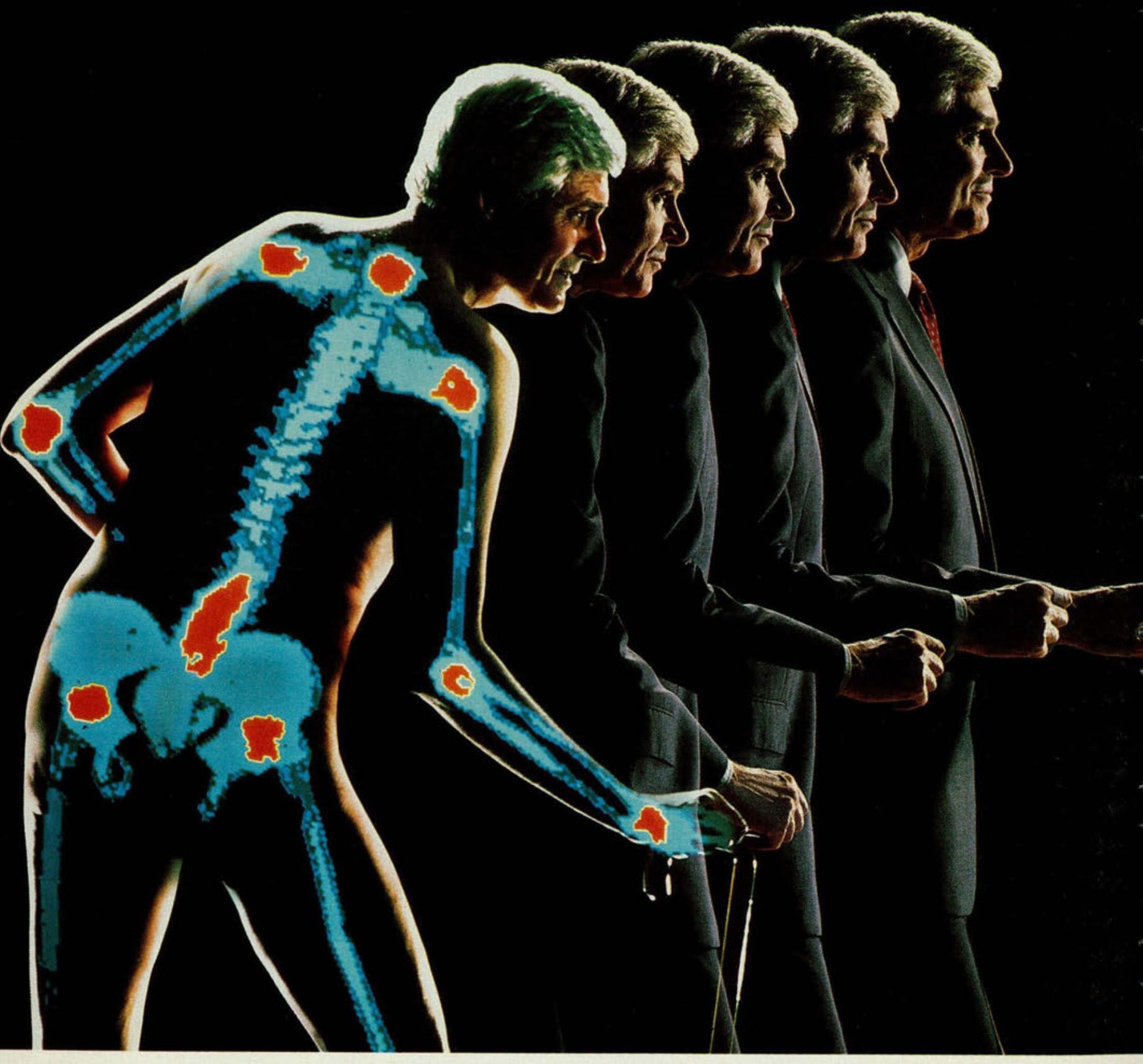




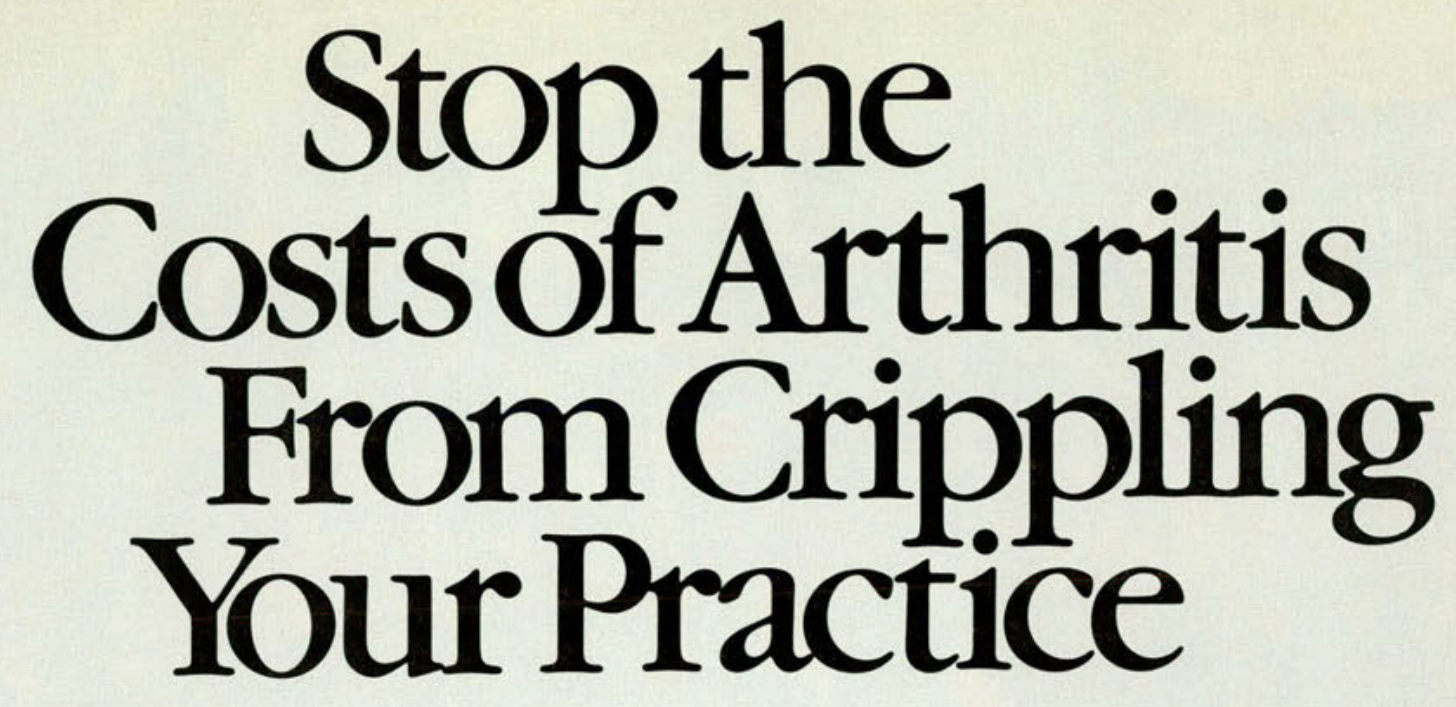

FELDENE $^{*}$ (piroxicam) is one of the lower priced prescription antiarthritic medications, when the most common daily doses are compared. ${ }^{1}$ High compliance makes it even more cost effective. ${ }^{2}$

When prescribing a nonsteroidal antiinflammatory drug (NSAID), not only is the initial cost important. There are also hidden costs to consider - including the cost of finding the right medication at the right dose. FELDENE can help reduce some of these costs. Here's how...

\section{- Speed}

FELDENE works quickly. ${ }^{3}$ With a simple 20-mg once-daily dosage, you don't have to titrate. FELDENE doesn't waste time. Yours or your patient's.

\section{- Compliance}

The strongest predictor of patient compliance is the number of tablets or capsules prescribed per day, and FELDENE is the only once-daily NSAID. In a study evaluating patient compliance with their NSAID regimen, compliance among patients on q.d. therapy was $30 \%$ greater than among patients on q.i.d. therapy. ${ }^{2}$

\section{- Effectiveness}

In a large multicenter study, among more than 3,000 osteoarthritis patients, over $85 \%$ had a good to excellent response with FELDENE. ${ }^{4}$

\section{- Patient Satisfaction}

Ninety-three percent of one group of osteoarthritis patients in a study reported feeling very good, good or fair - after a mean of 8.5 years on FELDENE (piroxicam). ${ }^{5}$ And satisfied patients are the most valuable asset to a practice.

As with other NSAIDs, the most common side effects are GI-related; in some patients, ulceration, bleeding, and perforation may occur.

Effectiveness and satisfaction translate into increased patient productivity - at home or at work.

That's Pharmacoeconomics. A Pfizer idea at work. It's our way of making and marketing medicines that satisfy both the needs of today's patient and the needs of today's physician. 


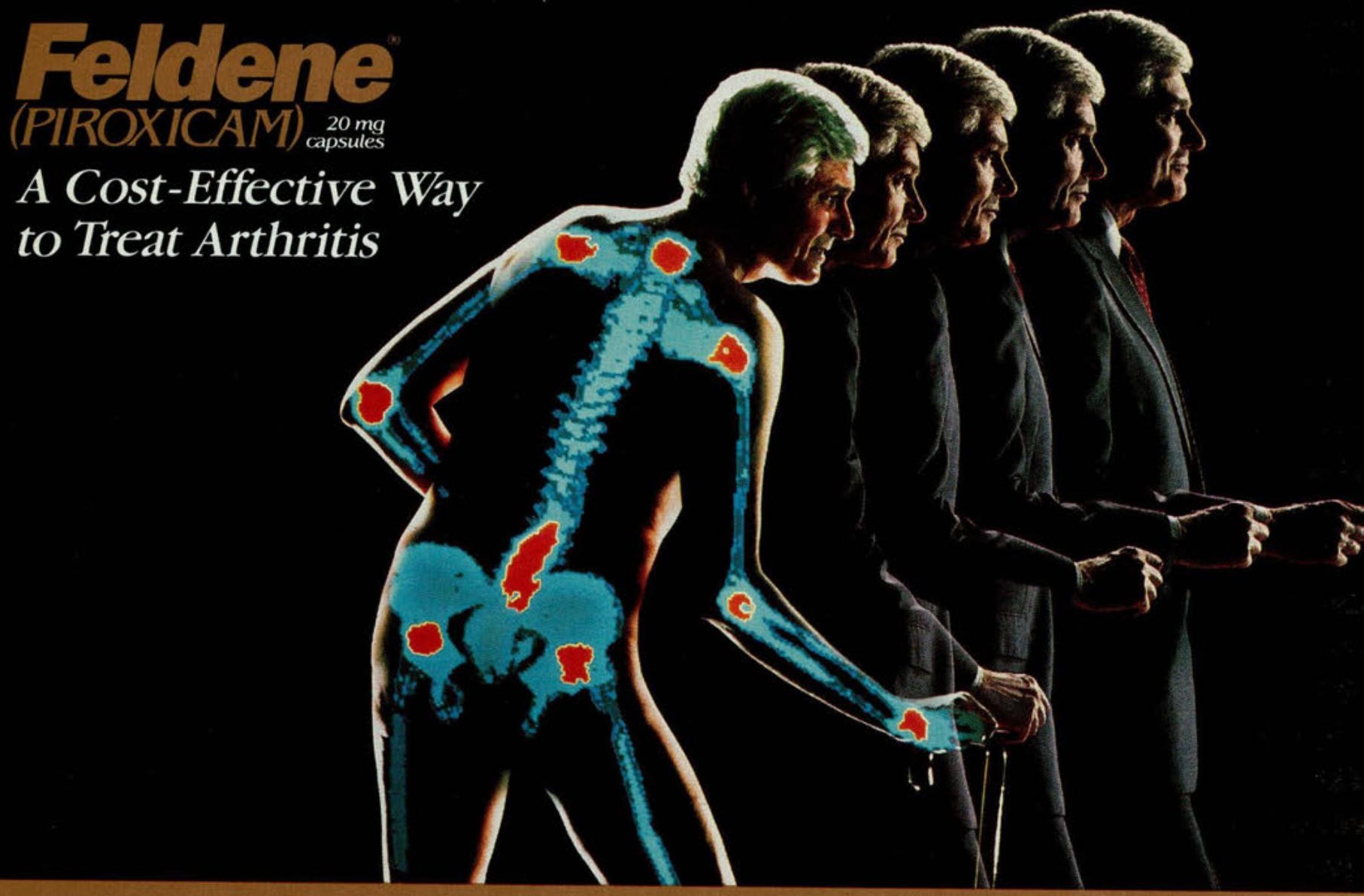

Reterences: 1. Data on file, Medical Department, Pfizer Laboratories Division, Pfizer Inc, New York. 2. Jacooss J. Bloor BS: Compliance and cost in NSAID therapy. Hosp Ther 1987: (special suppl): 32-39. 3. Ungetti M. Bianchi A, Ciarimbol

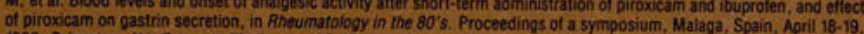

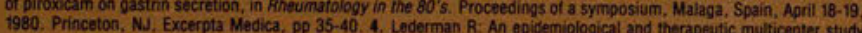

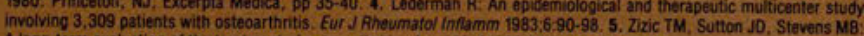

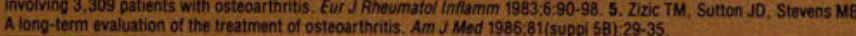
Briet Summary

FELEEME $\bullet$ (piroxicam) Captule:

CONTRAMOICAMONS: FELDENE (piroxicam) should not be used in patients who have previously exhibited hypersensitivity to it. or in individuals with the syndrome compis
or other nonsterodial anti-infliammatory druges WARkimGs: Peptic ulceration, pertoration, and G.L. bleeding - sometimes severe, and. in some instances fatal-have

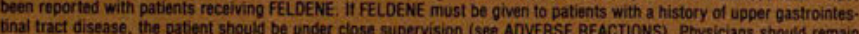
aiert for uiceration and bleeding in patients treated chronically with NSAIDS even in the absencer of previous Git tract

PAECAUTIONS: Renal Effects: As with other nonsteroidal ant-inflammatory drups. Iong-term administration of airoxican to animals has resulted in renal papillary necrosis and other a bnormal renal pattoloboy. In hummans, there have been report:

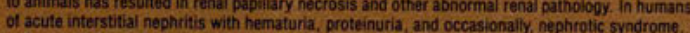

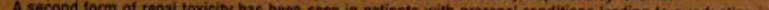

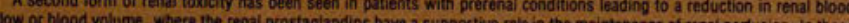

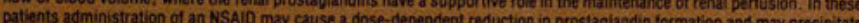

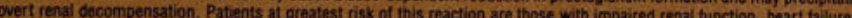
liver dystunction, those taking diuretics. and the eldert,

Because of extensive renal excretion of piroxicam and its biotranstormation products (less than $5 \%$ of the daily dose excreted unchangood), lower doses of piroxicam should be anticlipated in patients with impared renal function, and they

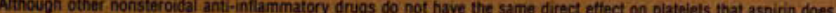
Urugs inhibiting prostaglandin biosynthesis do intertere with platelet function to some degree.

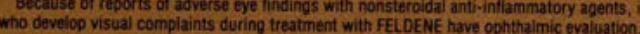

作

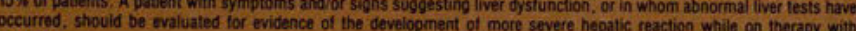

Severe hepatic reactions, including faundice and cases of tatal hepalitis, have been reported with FELDENE. Althougt

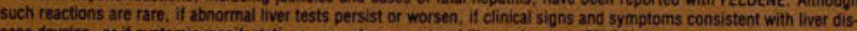

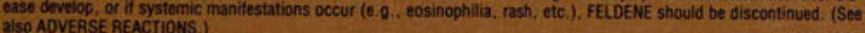
Aithough at the recommended dose of 20 my/day of FEL DENE increased tecal blood loss due to gastrointestinal imtation fid not occur, in about $4 \%$ of the patients treated with FELDENE alone or concomitantly with aspirin. reductions in hemo-

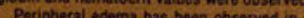

shouid he uf eed with A commination of deren accurred in coniunction with the use of FELOENE. These include arthralgias, pruritus. fever, tatigue, and rash inctuding vesiculo bullous reactions and extoliative dermattic

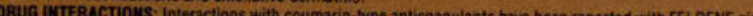
Therelore, physicians should closely monitor patients for a change in dosage requirernents when administering FELDENEE to patients on coumarin-type anticoagulants and other highily orolein-bound drugs"

Plasma ievels of piroxicam are depressed to approximately $80 \%$ of their normal values when FEIDENE is administered in conjunction with aspirin ( $3900 \mathrm{mg}$ day), but concomitant administration of antacids has no effect on piroxicam plasma

Nonsteridical anti-inflammatory agents, including FELDENE, have been reporteo to increase steady state plasma lithium evels. It is recommended that plasma lithium leveis be monifored when initiating, adjusting and discontinuing fELDENE Carcinogenesis, Chronic Animal Toricity and Impairment of Fertility. Subacute and chronic toxicity studies have been The out in rats, mice, oogs, and monkeys.

agents: renal gan mostert often seen was that characteristically associatec with the

in classicai studies in laboratory animals, pirroxicam did not show any teratogenic potentia.

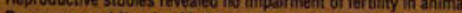

Pregnancy and Wursing Motherr: Like other drugs which inhibit the synthesis and release of prostaglandins, piroxicam adoministration continued late into pregnancy increased the incidence of dystocia and delayed parturition in animals. Gas

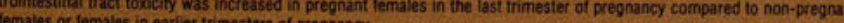

FELDENE (piroxicam) is not recommended for use in nursing mothers or in pregnant women because of the animal tind hygs and since salety for such use has not been established in humans

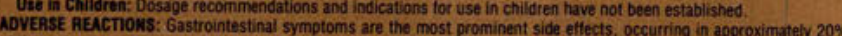
of the patients, which in most instances did not interfere with the course of therapy. Of the patients experiencing pastro intestinal side efftects, approximately $5 \%$ discontinued therapy with an overall incidence of peptic ulceration of about $1 \%$. Adverse roactions are isteed beliow by boay system for all patients in clinical trials with FEL DENE at doses of 20 moitay incilence Grater Than 1\%: The following adverse reactions occurred more trequenty than 1 in 100. andexia, epigastic distress: nausea; co

diarnea, abdominal pain, indigestion

Dermatologic: perritius, ras

Contral Nervous System; diziness, somnolence, vertigo

Body as a Whole: heascache, malaise

Speciar senses: tinnitus

Thry edema (see PRECAUTIONS)

- Reactions occurring in $3 \%$ to $9 \%$ of patients treated with FELDENE. Reactions occurring in $1 \%$ to $3 \%$ of patients are

Incidence Leas Tha 1\%: (Causal Relationship Probable: The following adverse reactions occurred less freevently than in 100. The probability exists that there is a causal relationship between fEL.DENE and these reactions gastrointestinal bieeding. pertoration and vilceration isee WARNINGSS. dry mouth

Hematological, thrombocytopenia, petechial rash, ecchymosis, bone marrow depression includino aplastic anemia

Dermatologic: sweating, erythema, bruising, desquamation, extoliative dermatitis. ervthema multiforme, toxic epiber. mal necrolysis. Stevens - Johnson syndrome, vesiculo bullous reactions, photoallergic skin reactions

nephrotic cynter

Body as a Whole pain (colic), tever, fu-like syndrome (see PRECAUTIONS

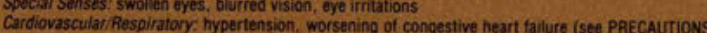

Metabolic: hypooglycemia, hypergolycemia, weight increase, weight decrease

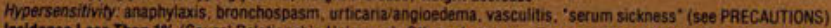
Inciconce Leass Than 1\%. (Causai Relationship Unknowa): Other adverse reactions were reported with a trequency of less han 1 in 100. Dut a causal relationship between FELDENE and the reaction could not be determined.

Dermatologic: onycholysis. loss of hair

Central Ner

Urogenilal System: dysuria

Body as a Whole: weakness

Hypersensitivity positive ANA

Special Senses: transient hearing loss

OVERDOSACE: in the ever trent

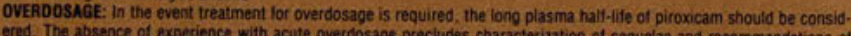
specific antidotal efficacy at this time. It is reasonable to assume that the standard measures of gastric evacuation and general supportive therapy would apply in adoition to supportive measures, the use of activated charcoal may effectively recuce the absorption and reabsorption of piroxicam. Experiments in doos have demonstrated that the use of multiple-Cose 11 hours and reduce the systemic biaavaliability of piroxicam by as much as $37 \%$ when activated charccoal is is given as late as 6 hours after administration of piroxicam. ADMIMISTRANON ANO DOSAGE: Rheumatoid Arthrtis. Osteoarthritis: It is recommended Imat FELDENE therapy be initiated and maintained at a single daly dose of $20 \mathrm{mg}$. If desired, the daily dose may be divided.

More detailed protessional information avaliable on request
Mons 
ing osteopathic medical education as well as undergraduate osteopathic education.

By developing progressively rigorous standards and methods of documentation, the AOA effectively became the watchdog of the osteopathic profession. These activities did much to convince both the public and legislators of the improved quality of osteopathic medical education and high standard of healthcare that the osteopathic profession was able to give.

In the mid-1960s, the concern for quality in accrediting procedures that had been shown by the AOA and the Bureau of Professional Education made an impact on the National Commission on Accrediting, now known as the Council on Postsecondary Accreditation (COPA), and on other national agencies concerned with education in the health professions.

COPA is the nongovernmental agency recognized by higher education institutions to approve and recognize national agencies for accreditation purposes. In 1967, COPA for the first time recognized the AOA as the official agency for accreditation of osteopathic medical education. While the association had, in effect, been acting in this capacity since its inception, this was the first time its actions were sanctioned by a higher educational authority.

Following this action, the AOA Board of Trustees, through its Department of Professional Affairs, delegated the responsibility for accreditation in a number of areas of osteopathic medical education to the Bureau of Professional Education. A subunit of this bureau, the Committee on Colleges, was charged with the responsibility of inspecting those institutions awarding the DO degree for accreditation of their educational programs.

Recognition by COPA was a first but significant step forward for educational programs within the osteopathic profession. Another even greater step quickly followed.

The federal government was expressing interest at that time in education at all levels, especially professional medical education. In 1969, the US Office of Education (USOE) examined the organizational structure and implementing documents of the Bureau. It then granted this body official status as the accrediting agency for osteopathic medical education. The USOE further recognized the Committee on Colleges as the inspecting body, and the AOA Board of Trustees as the appeals body.

The USOE (now the US Department of Education, DOE) does not grant accreditation status in perpetuity, but reviews organizations every 5 years. Those that do not meet DOE requirements are reviewed more frequently. The AOA has successfully completed each of its subsequent 5 -year renewal cycles. In July 1989 , the AOA once again received approval as the accrediting body for osteopathic medical education for another 5-year term.

Presently, the Bureau coordinates the activities of three committees that deal with various phases of osteopathic medical education (see Appendix I for committee membership):

- Committee on Colleges, the evaluating unit of predoctorate education;

- Committee on Postdoctoral Training, the evaluating unit of internships, residencies, preceptorships, and other postdoctorate programs;

- Committee on Continuing Medical Education, the unit that evaluates programs and recommends approval of CME credits. 